\title{
Acción e institución: hacia una comprensión paradójica de la acción política
}

Action and Institution: Towards a Paradoxical Understanding of Political Action

Christian Julián Fajardo-Carrillo

Universidad de los Andes (Colombia)

Recibido: 2014-08-29

Envío a pares: 2014-09-18

Aprobado por pares: 2014-10-10

Aceptado: 2014-11-13

Pensamiento y Cultura | ISSN: 0123-0999 | eISSN: 2027-5331

pensam.cult | Vol. 18-1 | Junio de 2015 | pp. 46-75

DOI: $10.5294 /$ pecu.2015.18.1.2

- Este artículo es uno de los productos de una investigación respaldada por Colciencias en el marco del programa Jóvenes Investigadores. Correo electrónico: cj.fajardo22@uniandes.edu.co. 


\section{Acción e institución: hacia una comprensión paradójica de la acción política}

Resumen: este artículo busca esbozar algunas líneas interpretativas en torno a una comprensión disensual de la institución y del sentido que producen los actos políticos emancipatorios. Teniendo en cuenta tal objetivo, propongo tomar distancia de un enfoque predominante en la filosofía política contemporánea, de corte benjaminiano, que pretende denunciar la violencia que se produce en el sentido y en la institución misma. Aunque este enfoque reconoce que el fundamento último de las instituciones es aquello que excede lo jurídico, el pensador alemán busca finalmente mostrar una oposición tajante entre la lógica de las instituciones y la lógica de la interrupción de las instituciones. Ahora bien, a partir de este distanciamiento, y siguiendo algunos aportes de Arendt, Rancière, Butler y Tassin, la hipótesis fundamental que pondrá a prueba este artículo consiste en mostrar que la acción, por un lado, al producir un tipo particular de sentido, instituye relaciones, y por otro, se sirve de sentidos e instituciones previamente existentes para encontrar sus modos de mostración. Esta dinámica de institución de relaciones y de usos de instituciones previamente existentes nos introduce, así, en una comprensión disensual de la institución que, si bien no pretende asegurar a la acción misma, sí ofrece las condiciones de posibilidad para que la acción tenga lugar.

Palabras clave: acción; institución; sentido; disenso; producción de sentido; política.

\section{Action and Institution: Towards a Paradoxical Understanding of Political Action}

Abstract: The article describes several lines of interpretation with regard to a disensual understanding of the institution and the sense or perception produced by emancipatory political acts. With this in mind, the author proposes distancing himself from a predominant Benjaminian approach in contemporary political philosophy that aims to denounce the violence produced in sense or perception and in the institution itself. Although this approach recognizes the ultimate basis of institutions goes beyond the legal aspect, the German philosopher ultimately tries to draw a sharp contrast between the logic of institutions and the logic of interrupting them. Accordingly, from this distance and pursuant to several contributions from Arendt, Rancière, Butler and Tassin, the fundamental hypothesis challenging this article it is to show that action, by producing a particular kind of sense or perception, establishes relationships and also makes use previously existing perceptions and institutions to find its 
modes of expression. This dynamic of instituting relationships and making use of previously existing institutions introduces us to a disensual understanding of the institution which, although not intended to ensure action itself, does offer the conditions of possibility for action to take place.

Keywords: action; institution; sense disense; production of sense; politics.

Walter Benjamin (2009a) en su ensayo Para una crítica de la violencia plantea la necesidad de investigar la relación entre violencia e institución desde la perspectiva del enfoque positivista del derecho, pues, en tal aproximación la relación entre violencia y derecho parece plantearse respecto de una paradoja que define la existencia del derecho mismo. La paradoja es la siguiente: el derecho cobra existencia cuando se produce una distinción clara entre violencia legítima y violencia no legítima, es decir, en el instante en el que los medios de la violencia están codificados por un ordenamiento jurídico, que distingue unos actos sujetos a fines naturales - ilegítimos- y otros sujetos a fines de derecho legítimos- No obstante, al parecer, lo que hace posible la existencia del derecho como codificación de la violencia legítima es una violencia exterior al derecho, es decir, una violencia natural que escapa a toda codificación, pero que funda al derecho mismo. De ahí cobra consistencia la distinción benjaminiana entre violencia fundadora y violencia conservadora de derecho.

La primera de ellas es aquella violencia prototípica que funda y produce relaciones jurídicas (rechtsetzend) - sin ser ella una violencia codificada y reglamentada por la ley-. La segunda violencia, en cambio, es aquella que mantiene ese orden fundado e instituido distinguiendo aquello legítimo y aquello que no es legítimo para fines de derecho (rechtserhaltend). En últimas, la violencia conservadora del derecho, que se codifica a partir de los ordenamientos jurídicos, le debe su existencia a una violencia primordial y exterior al derecho. No obstante, para asegurar su existencia, el derecho expulsa de sí las violencias prototípicas y fundantes que no pertenecen a él, mostrándonos que la única violencia fundante es aquella que es ejercida por él, es decir, por la ley misma que se autosuspende para preservar el orden jurídico. De ahí que 
cobren consistencia las siguientes palabras de Benjamin: "El Estado le teme, más que a cualquier otra cosa, a que esta violencia [la violencia natural y exterior al Estado] funde derecho en el mismo grado en que él debe fundarlo" $(2009,42)$.

El estudio sobre la legitimidad de los medios de la violencia nos arroja, entonces, a la siguiente consecuencia: la única violencia exterior al Estado que se admite es aquella que permite asegurar la existencia del Estado mismo, es decir, del orden jurídico.

Tenemos así que la legitimidad de la violencia en un orden jurídico tiene validez cuando, en los medios de la violencia, existe una violencia fundadora y una violencia conservadora del Estado. Esta distinción traza, entonces, una frontera de sentido que separa, por un lado, una violencia legítima consistente en conservar y fundar derecho en la lógica jurídica y, por otro, una violencia excesiva, que pone en peligro la existencia del orden jurídico mismo. Siguiendo, en parte, esta misma línea argumentativa, Schmitt (2008) nos dice que esta violencia legítima se puede comprender bajo la noción de 'estado de excepción'. Para el jurista alemán, la única violencia fundante que admite el orden institucional en casos de emergencia es aquella que excede el orden jurídico, pero al mismo tiempo conservando los fines de derecho. Por eso, "en vista de que el estado de excepción sigue siendo algo distinto de la anarquía y el caos, aún subsiste un orden en el sentido jurídico, si bien no se trata de un orden jurídico" (Schmitt 2008, 27). La crítica de la violencia consiste, entonces, en dar cuenta de que el orden jurídico se produce una vez se han trazado unas fronteras de sentido que diferencian, por un lado, una violencia caótica y excesiva y, por otro, una violencia legítima, que permite fundar o conservar un orden determinado. En últimas, la institución jurídica nace en el instante en el que se presupone una oposición tajante entre la ley y su afuera o entre la violencia legítima y la violencia no legítima. Tenemos así que la institución, para la crítica benjaminiana, muestra que el derecho solo subsiste cuando ciertas violencias se han institucionalizado ocultando y expulsando otros modos de acción, que resultan excesivos para el orden jurídico. A esta violencia que fija sentido habría que oponerle, a juicio de Benjamin, una violencia sin medios y sin fines, es decir, una violencia que quiebre con los criterios 
de un derecho que distingue lo que pertenece y lo que no pertenece al orden jurídico. Por eso, esta violencia, que Benjamin llama violencia divina, tendrá el destino de oponerse a la violencia fundante y conservadora del derecho - violencia mítica-. En sus palabras,

[...] si la violencia mítica funda derecho, la violencia divina lo destruye (rechtsvernichtend). Si la primera establece límites, la segunda los destruye de forma ilimitada. Si la violencia mítica culpa (verschuldend) y expía (sühnend) al mismo tiempo, la divina sólo absuelve (entsünend). Si una amenaza, la otra golpea. Si aquella es sangrienta (blutig), la segunda es letal sin derramar sangre (auf unblutige Weise) (2009, 57-58).

Esta violencia sin representación y sin institución tendría como única pretensión destruir la lógica de fines y medios con los que opera la violencia del derecho y de las instituciones. De ahí que podamos decir que una suerte de emancipación tendría que ver más con una interrupción de los dispositivos jurídicos que cercan la vida del ser viviente a su condición de "mera vida".

A una conclusión similar habría llegado una tendencia visible de la filosofía política contemporánea. Pues, para autores como Agamben (2006), Esposito (2006) o Nancy (1996), aquello que interrumpe la lógica representativa del sentido que se ve reflejada en la institución debe comprenderse a partir del supuesto de una diferencia fundamental entre lo jurídico y lo que excede lo jurídico o, mejor aún, entre una esfera óntica del sentido fijado y una esfera ontológica de la contingencia última que escapa de toda fijación representativa. ${ }^{1}$ La interrupción de la

1 En un estudio muy cuidadoso Oliver Marchart (2009), toma en cuenta la diferencia ontológica entre lo político y la política, que se puede ver en el pensamiento de Nancy, Lefort, Badiou y Laclau. Una de sus apuestas consiste en mostrar que el plano de 'lo político' es una suerte de fundamento contingente de la fijación de sentido, que presupone el plano óntico de la lógica institucional o de lo social. Esta distinción entre lo social y lo político o entre la política y lo político nos arroja a una comprensión posfundacional de la política, que pretende indagar los fundamentos cuasitrascendentales de la acción política, es decir, el lado ontológico y contingente de la acción emancipatoria. Este juego oposicional nos va a decir que la lógica de la política o lo social obtienen su fundamento de una contingencia primordial — de lo político-. 
lógica institucional, para este enfoque, consistiría en exhibir que lo político escapa de la lógica de fines y medios de las instituciones o de lo que Benjamin llama violencia mítica. Tenemos así que para este enfoque hay una rotunda separación entre lo político y la institución, pues, a pesar de que aquel hace posible que exista la institución, su modo de funcionamiento es radicalmente distinto. Lo político, en este caso, tendría la labor de mostrar que hay algo que escapa al sentido, o en otras palabras, en esta lógica se pone de manifiesto unos modos determinados de pensar lo común que expresan su rotunda diferencia frente a la lógica del sentido fijado por la institución o por las fronteras de sentido que hacen posible que exista un orden jurídico. No obstante, ¿a qué consecuencias nos arroja esta rotunda oposición entre estas lógicas? ¿Qué estaría en juego en esta perspectiva crítica que nos hace pensar una oposición tajante entre institución y lo político? ¿Podríamos reformular esta relación más allá de su mera oposición sin caer en el juego reformista de mostrar que lo político o la acción política permite modular nuestras instituciones hacia un porvenir cada vez más prometedor?

Para ir elaborando las anteriores preguntas resulta preciso afirmar, a modo de hipótesis, que la oposición entre violencias que el pensamiento que Benjamin despliega en Hacia una crítica de la violencia (2009a) y la tradición posfundacional que se ancla en la diferencia política parece no poner en cuestión los criterios que trazan una diferencia radical entre la institución y su afuera, según esta hipótesis, la acción política (como debería interpretarse lo político), más allá de buscar manifestar su rotunda oposición a la institución, parece ser un proceso en el que se pone en cuestión las fronteras de sentido que separa una institución anclada a una univocidad de sentido y un afuera puro que escapa de todo régimen óntico de representación. Esta problematización de las fronteras de sentido que separan la institución y su afuera nos muestra que la acción política es un proceso en el que se instituye un mundo sensible y, asimismo, se sirve de instituciones para poder manifestarse. De ahí resulta relevante la afir-

No obstante, aquello que hace imposible el cierre de sentido es la contingencia propia de lo político. Marchart (2009) llega al punto de decir, junto con la perspectiva Zizek, que el hecho de que existe un subsistema en la sociedad es una suerte de "síntoma" de aquello que escapa y hace de lo político algo fundable o totalmente fundable. 
mación de Judith Butler que nos dice que la acción política plantea una suerte de paradoja, porque "no podemos actuar sin apoyos, y sin embargo tenemos que luchar por los apoyos que nos permiten actuar" $(2012,9)$. Tales apoyos no son más que mundos de sentido sedimentados, que se manifiestan en derechos consagrados por ordenamientos constitucionales o por imaginarios comunes. Para ilustrar con la suficiente claridad esta mutua presuposición entre acción e institución, basta dar cuenta de cómo las acciones emancipatorias en el momento de luchar por ciertas razones, tales como el acceso a sistemas de seguridad social, la soberanía alimentaria, el respeto a la autodeterminación de los pueblos, etcétera, se presupone que esas exigencias son las condiciones de posibilidad para que la acción tenga lugar. La acción política parece ser una fútil manifestación que, en ciertas ocasiones, está tenuemente asegurada por instituciones que en algún momento fueron producidas por acciones pasadas. La acción política, en este caso, no se opone a la institución, sino más bien crea un escenario en el que se desestabilizan las fronteras de sentido que oponen la institución y su afuera, porque, en algunos casos, ciertos derechos o imaginarios instituidos permiten que la acción tenga lugar. Desde esta perspectiva, los derechos se vuelven razones para la manifestación de mundos posibles y de nuevos trazados de sentido.

Esto nos arroja, entonces, a que lo político, más allá de ser una suerte de manifestación de medios sin fin o de fines sin medios, es un proceso en el que se desestabilizan los criterios sensibles que separan un mundo instituido de un mundo instituyente y, para eso, esta aproximación a las prácticas emancipatorias nos invita a reinterpretar el trazo dicotómico que separa acción e institución. Para pensar esta relación, resulta preciso mostrar que lo político, más allá de ser una suerte de fundamento cuasitrascendental que demuestra que las condiciones de posibilidad del sentido son sus condiciones de imposibilidad, es una acción que reensambla nuestro mundo común haciendo confluir regímenes de habla y de prácticas heterogéneos. Este encuentro de heterogéneos instituye relaciones y, asimismo, se apoya en modos de sentido instituidos. Para demostrar este punto de vista, nos serviremos de ciertas aproximaciones del pensamiento de Arendt (2013), Rancière (2010), Tassin (2012), Butler (2012), Deleuze y Guattari (2005). Como se verá, 
las preguntas que dejan abiertas estos pensadores nos invitan a reelaborar la relación entre institución y acción, que se pone en marcha en las acciones políticas emancipatorias.

El orden del texto será, entonces, el siguiente. En primer lugar, nos detendremos en el modo en que lo político, comprendido respecto de la acción política, instituye un conjunto de mundos posibles y ciertas coordenadas de sentido. Como se verá, esta institución desestabiliza los supuestos que hacen estable un mundo común con una poética que traza una serie de coordenadas temporales de sentido que afectan nuestro mundo común a través de una escena disensual. La acción política, más allá de denunciar la violencia detrás del sentido, o incluso más allá de manifestar la diferencia entre lo político y la política, instituye un mundo común que desestabiliza las fronteras que separan la violencia de la institución y la irrepresentabilidad de su afuera. En segundo lugar, se caracterizará cómo una acción política se apoya en elementos instituidos que le otorgan cierto sentido a nuestro mundo común. Desde esta perspectiva, mostraremos que la acción política, además de instituir un conjunto de relaciones, hace uso de palabras y practicas previamente existentes - como el mismo derecho-, para escenificar una escena a través de figuras y actos de habla que redistribuyen los criterios que hacían posible un mundo instituido con distinciones evidentes entre lo institucional y lo no institucional o la acción y la institución. Estos dos modos de darle consistencia a la relación entre acción e institución nos permitirán, en tercer lugar, establecer algunas consecuencias respecto de la efectividad y la posibilidad que tiene la acción de afectar nuestro mundo común.

\section{Institución del disenso}

Hannah Arendt (2013), en el último capítulo de su ensayo Sobre la revolución, nos explica que el espíritu revolucionario de la época moderna tuvo al menos dos preocupaciones completamente anudadas. La primera de ellas consistía en fundar un nuevo cuerpo político que garantizara un espacio para el ejercicio de las libertades políticas, y la segunda pretendía mantener una durabilidad del espíritu de novedad 
de la revolución misma. En un principio, a juicio de Arendt, no había contradicción alguna dentro de esta preocupación, pues, si por algo se caracterizaba el entusiasmo transformador de los actos que les dieron origen a las revoluciones, fue precisamente la preocupación por garantizar una permanencia a los actos que fundaron un nuevo cuerpo político. $\mathrm{O}$, en otras palabras, las apuestas emancipatorias plantearon la posibilidad de instituir un nuevo modo de gobierno para asegurar la novedad y darle una permanencia en el tiempo. No obstante, de acuerdo con Arendt, una vez hecha la transformación, el pensamiento revolucionario entra en contradicción con el entusiasmo transformador y el espíritu emancipatorio que hizo la revolución posible. Por eso, en las repúblicas que se fundaban parecía entonces no existir "ningún lugar destinado al ejercicio de aquellas cualidades que habían sido precisamente el instrumento con el que había[n] sido construida[s]" (2012, 383), porque, a juicio de los padres fundadores de la república norteamericana, el precio que tenían que pagar los procesos emancipatorios para mantenerse perdurables en el tiempo tendría que ser aquella "libertad de acción" que la hizo posible. De ahí que cobren sentido las siguientes palabras de Arendt:

Puede parecer paradójico, pero lo cierto es que el espíritu revolucionario comenzó a marchitarse en América bajo el impacto de la Revolución, siendo la propia Constitución, la mayor hazaña del pueblo americano, la que terminó por despojarlos de su bien más preciado $(2012,395)$.

Un proceso similar se vivió en la época de la Revolución francesa. Pero a diferencia del intento casi inmediato de hacer desaparecer el espíritu revolucionario, como se puso en evidencia en el ejemplo norteamericano, en Francia se logró experimentar políticamente con un conjunto de instituciones democráticas, como los clubes y las sociedades revolucionarias. En ellas, a juicio de Arendt, se ejercía esa libertad política que hizo emerger la Revolución como un proceso emancipatorio. No obstante, después del verano de 1793, Robespierre - defensor acérrimo de las sociedades y los clubes- se vuelve jefe de la Revolución y decide 
perseguir aquellas instituciones democráticas para hacer de los jacobinos los diputados que ocupaban el interés único de toda la nación. Una vez más, el ejemplo francés nos muestra que los procesos revolucionarios, en algún momento, se tendrán que deshacer de aquello que los hizo posibles para lograr que el cuerpo político, que nació de tales actos, se mantenga en el tiempo.

La contradicción del pensamiento revolucionario quizá hace eco en la apuesta schmittiana por comprender el derecho desde la perspectiva del estado de excepción, porque el pensamiento revolucionario termina suscribiendo cierta tesis contrarrevolucionaria y apuesta al pensamiento arendtiano de la acción, según la cual la norma necesita un medio homogéneo para adquirir validez. Al contrario, las normas carecerían de concreción con el medio al que buscan aplicarse; o en palabras de Schmitt,

[...] no existe una norma que pueda aplicarse al caos. Debe establecerse el orden para que el orden jurídico tenga sentido. Hay que crear una situación normal, y es el soberano el que decide de manera definitiva si este estado normal realmente está dado $(2008,28)$.

La acción revolucionaria, más allá de ser, entonces, un espíritu que abogó por el cambio de los modos de gobierno, terminó pareciéndose más a la decisión soberana que produce derecho sin ser ella misma derecho. La institución así, desde esta perspectiva, terminó siendo el producto de una acción fundadora que pretendía hacer coincidir un conjunto de palabras instituidas - como la libertad, la soberanía y la igualdad- con un escenario homogéneo para que estas tengan un sentido petrificado. La dimensión lingüística de la excepción que ya exploró Agamben (2006)² nos explica que la decisión, además de

2 Giorgio Agamben en Homo sacer: poder soberano y nuda vida explica cómo la decisión soberana presupone lo no jurídico al igual que el lenguaje presupone lo no lingüístico, porque antes que nada la decisión o todo sentido lingüístico debe presuponer ciertas condiciones que hacen posible la existencia de tal o cual sentido o de tal o cual ley. En palabras del filósofo italiano, "la excepción soberana (como zona de indiferencia entre naturaleza y derecho) es la presuposición de la referencia jurídica en la forma de su 
instaurar un orden jurídico de acuerdo con un medio construido por ella misma, instituye un régimen de sentido que crea las condiciones de vida normales para que una norma tenga operatividad. Por eso, "el derecho tiene carácter normativo, es 'norma' (en el sentido propio de 'escuadra') no porque ordene y prescriba, sino en cuanto debe, sobre todo, crear el ámbito de la propia referencia en la vida real, normalizarla" (Agamben 2006, 40).

La excepción soberana y la contradicción del pensamiento revolucionario que Arendt denuncia contundentemente parecen, entonces, suscribir una oposición entre acción e institución en el instante en que se conforma un cuerpo político, porque la fundación de un orden necesita un referente que denotar, y tal orden no es otro que el medio instituido para que la norma tenga validez y vigencia. $\mathrm{O}$ en otras palabras, la oposición entre la institución y su afuera pone de manifiesto una distribución del sentido en el que las palabras encuentran un medio por el que circulan al denotar y significar cosas y referentes. De ahí que la excepción soberana demanda, entonces, un derecho perfectamente adecuado a una realidad instituida, ya sea por la acción revolucionaria, ya sea por la decisión soberana misma. Lo anterior nos arroja a que toda apuesta por romper con aquella armonía entre el orden de las palabras y el orden de las cosas o entre el orden de las normas y de la realidad resquebraja el cuerpo político, que se empeña por separar la esfera de la representación pública y la esfera del goce privado, porque toda demanda por parte del pueblo que no se canalice a través del sistema de partidos empezó a ser concebida - para los mismos revolucionarios profesionales - como una organización sin institución excedentaria que altera el orden de un cuerpo político.

Esta fue la trágica historia de los organismos de participación directa que nacieron espontáneamente de las revoluciones modernas - Arendt se refiere a la francesa, a la rusa y a la húngara-. Los sistemas de consejos fueron, por tanto, perseguidos por los defensores de la Revolución, porque estos órganos confundían las fronteras entre institución y acción y asimismo entre las demandas privadas y las demandas

suspensión" (Agamben 2006, 34). La excepción, así como el lenguaje, presupone, entonces, una referencia que se instituye en la suspensión de todo orden. 
públicas, porque "los consejos siempre fueron tanto órganos de orden como de acción [...] no cabe duda de que cada individuo tuvo su propia esfera de acción y podía contemplar, por así decirlo, con sus propios ojos su contribución personal a los sucesos del día" (Arendt 2013, 436). La restauración del orden de los recién fundados cuerpos políticos se opuso a la efervescencia popular que se manifestó en la creación de organismos de participación directa. No obstante, ¿necesariamente la institución de un cuerpo permanente nos arroja a un rechazo rotundo de la acción? ¿Podemos concebir a la acción emancipatoria más allá de su oposición estricta a lo instituido, como nos lo muestra el ejemplo schmittiano y la experiencia revolucionaria analizada por Arendt?

Para caracterizar la relación entre institución y acción desde una perspectiva no dicotómica, es decir que vaya más allá de la contradicción del pensamiento revolucionario o de la noción de 'estado de excepción', parecería más acertado, en términos analíticos, decir que la acción emancipatoria instituye un conjunto de relaciones y de distribuciones del sentido. Ahora bien, diremos, siguiendo a Jacques Rancière, que esta acción no escapa de toda institución ni tampoco pretende manifestar una oposición perfecta a la lógica mítica del derecho — como ya lo subrayaba Benjamin (2009a)—, sino más bien es "una institución que tiene por objetivo el acrecentamiento del poder de cualquiera (n'importe qui) (Rancière 2012, 217). O dicho de otro modo, esta institución de la acción política es la institución de una parte de los sin parte (part de sans-part). Pero ¿cómo comprender la institución respecto del poder de cualquiera? ¿Qué tipo de relación entre institución y acción podemos encontrar en una institución que pretende manifestar una fórmula paradójica como "una parte de los que no tienen parte"? Rancière (2010) intenta demostrar que la política o la acción emancipatoria es un proceso en el que se pone de manifiesto una suerte de cuasipalabra, de cuasicuerpo o de cuasipráctica, porque la acción política más allá de demostrar que hay una rotunda separación entre lo político y la política - en el sentido de la diferencia política u ontológica de Marchart y Álvarez (2009)—, es la reconfiguración de nuestro campo de sensibilidad, que hace emerger cuerpos que no son estrictamente cuerpos o de palabras que 
no son estrictamente palabras. Ahora bien, ¿cómo comprender esta emergencia o institución de cuasicuerpos, palabras y prácticas?

Para exponer a cabalidad aquello que está en juego en la acción política desde la perspectiva de Rancière, es preciso partir del presupuesto de que la política reconfigura o refigura un campo de visibilidad previamente existente. Este campo "previamente existente" es llamado policía. La policía es una configuración del sentido que marca distinciones, en la medida en que hace visible, audible e inteligible un conjunto de palabras y de prácticas dentro de un campo de visibilidad específico que tiene la característica de establecer modos lógicos de pertenencia y de no pertenencia. De ahí que, para una distribución policial de nuestra sensibilidad, existe, por un lado, el ruido y la palabra o exista una parte separada de la no parte. La policía es en consecuencia un modo de concebir lo común, que le ofrece una permanencia y una necesidad específica a un orden dado, al contrario no habría la posibilidad de que nuestro lenguaje denote cosas y prácticas que nos son comunes. Llamamos, por ejemplo, públicas a un conjunto de prácticas separadas de otras que consideramos privadas. O incluso, a través de un modo policial de configurar la realidad, podemos escuchar aquello que es audible o ver aquello que es visible. Desde esta perspectiva específica de la configuración de nuestro mundo común, podríamos decir que el afán de la decisión soberana de establecer un medio adecuado para que una norma tenga validez obedece a una distribución policial de lo sensible, pues su pretensión consiste en mostrar que nuestras palabras y normas tienen objetos y prácticas para nombrar. De ahí que los derechos sean siempre de ciudadanos, es decir, de seres humanos perfectamente pertenecientes a la parte de la ciudadanía. Ahora bien, la acción política o la institución de la política es un proceso excedentario, que desestabiliza las fronteras policiales de sentido, las cuales separan una institución propia de las instituciones o una acción propia de la manifestación de la pluralidad humana, porque aquello que instituye la política es una suerte de desarmonía o de falta de armonía (més-entente) en nuestro orden policial de sentido. La acción política por ende reconfigura nuestro orden de sensibilidad dividiendo el sentido y produciendo una distancia (écart) entre una palabra y una cosa o entre una palabra y la cuenta de esa palabra (compte de ce parole). 
La política instituye en consecuencia escenas sin mucha consistencia para una distribución policial de lo sensible, porque formula enunciados como "los derechos de los que no tienen derechos", "la ciudadanía de los condenados de la tierra" o "incluso el poder de quienes no tienen poder". La política reconfigura las conexiones entre palabras y cosas -o entre palabras y su cuenta - para desestabilizar un mundo armónico en el que una palabra tiene un referente al qué denotar. No obstante, esta desarmonía o este desacuerdo sobre el sentido de un mundo dado no pretende instaurar un nuevo régimen de significación, sino más bien busca figurar un conjunto de contornos de sentido temporales que desestabilizan la pretendida lógica de un lenguaje de pertenencia y de no pertenencias. De ahí que la manifestación de la acción política visibilice un conflicto entre mundos, es decir, entre configuraciones de lo sensible.

Tenemos así que la acción política, al crear un conflicto sobre nuestros datos sensibles, instituye una situación de interlocución —más no oposición- entre dos mundos: el mundo del reparto policial y el mundo que crea nuevas conexiones entre sentidos y prácticas. Ahora bien, esta interlocución pone de manifiesto cómo dos conjuntos de actores comprenden y a la vez no comprenden lo que dicen los otros, es decir, pone en interlocución unos actores para los que los derechos de los ciudadanos son de los ciudadanos y otros actores para los que los derechos de los ciudadanos son de los no ciudadanos o de los oprimidos. De ahí que cobren relevancia las palabras de Rancière retomando la fábula brechtiana Santa Juana de los mataderos:

La fábula brechtiana se situaba en efecto en un universo en el que todas las nociones se dividían en dos. La moral cristiana se revelaba ineficaz para luchar contra la violencia del orden económico. Debía transformarse en una moral militante, que tomaba como criterio las necesidades de la lucha contra la opresión. El derecho de los oprimidos se oponía así al derecho cómplice de la opresión que defendían los policías rompehuelgas. La oposición de dos violencias era entonces también la oposición de dos morales y dos derechos (Rancière 2011, 135). 
Expresiones, tales como "la moral militante" o "los derechos de los oprimidos", desestabilizan la usual comprensión en la que la moral es cristiana y en la que el derecho es de los ciudadanos. Esta oposición, de la que nos habla la interpretación que hace Rancière (2011) de Brecht, es la institución de un intervalo o de una distancia que separa un juego de palabras y de prácticas de su sentido usual, es decir, un intervalo que separa un sentido para el que la institución es una suerte de andamiaje jurídico y una acción que por sí misma no instituye ningún sentido sino meramente lo interrumpe-, lo cual permite escenificar un espacio de inteligibilidad que no instituye un sentido unívoco de acuerdo con unos criterios " a priori", ni tampoco se pretende denunciar la violencia que está por detrás de todo sentido. El choque entre mundos heterogéneos o entre prácticas y palabras heterogéneas, que instituye la acción política, nos muestra combinaciones de palabras y de sentidos que desarticulan la armonía, la cual fija contornos diferenciales y claros para interpretar la realidad. Por eso, las palabras que instituye la acción política son siempre palabras que, para el mundo policial, no son palabras, puesto que no denotan su referente usual. La historia de estas escenas disensuales en el siglo XIX nos muestra una clara explicación de este proceso disensual, pues aquellas acciones buscaban

afirmar que la inscripción de la igualdad en la forma de "igualdad de los hombres y los ciudadanos" ante la ley definía una esfera de comunidad y de publicidad que incluía los "asuntos" del trabajo y determinaba el espacio de su ejercicio como dependiente de la discusión pública entre sujetos específicos (Rancière 2010, 71).

La acción política crea, desde esa aproximación, un escenario disensual en el que una palabra deja de significar su referente usual. Por eso, "la igualdad de los hombres y los ciudadanos" empezó a "denotar" un conjunto de prácticas que usualmente eran concebidas como pertenecientes a la esfera de lo privado y carentes de adquirir una dimensión pública. Las relaciones laborales empezaron, en las luchas obreras, a hacer parte de las discusiones públicas, porque lo obreros se presentaban como sujetos de derechos derrocando la idea 
de que las relaciones laborales obedecen a una estricta relación jurídica de subordinación.

Tenemos así que la paradoja del pensamiento revolucionario y la lógica del decisionismo de Schmitt (2008) exhiben no una apuesta estrictamente política, sino más bien policial, porque el hecho de partir del supuesto de que la acción necesariamente debe preparar un orden instituido es emblemática de la perspectiva policial de interpretar la realidad, pues se parte de un presupuesto que opone acción e institución como si la acción fuera una suerte de "partera" del orden instituido, pero que se diferencia de una forma radical de dicho orden. La lógica de la acción política, en cambio, desestabiliza las jerarquías de sentido como si no hubiera orden alguno que subordinase una clase de palabra a otra o una clase de práctica a otra. Rancière (2011) nos dice que, en esta desestabilización, se presupone una igualdad de cualquiera con cualquiera. Ahora bien, esta igualdad de la acción no es formal ni existe algo que la asegure totalmente, ya que ella misma instituye una escena específica que construye una suerte de médium sensible, en el que prácticas y palabras, que no tenían razón alguna para encontrarse, se encuentren.

Con miras a esclarecer la institución de dicho médium, quizá sea preciso traer un pasaje ejemplar de El desacuerdo. Rancière (2010) nos dice que desde la perspectiva de un reparto policial de lo sensible tiene cabida la afirmación de Aristóteles (2003) en La política, según la cual, en el orden del habla, hay quienes comprenden la lengua (aisthesis) y quienes la poseen (hexis). De esta manera, "el esclavo es aquél que participa en la comunidad del lenguaje bajo la forma de la comprensión (aisthesis), no de la posesión (hexis) [traducción modificada] (Rancière 1995 38). Tenemos así que el lenguaje, en un esquema policial, además de organizar cierto tipo de actos de habla, jerarquiza los cuerpos que emiten tales palabras. Desde esta perspectiva, cobran sentido las relaciones de jerarquía que se entablan en las escenas contemporáneas del "mundo laboral", porque los jefes de una fábrica o de una empresa suponen que sus trabajadores o subordinados - contractualmenteno deben hacer otra cosa que "ejecutar órdenes". De ahí que, para que la jerarquía en una fábrica o de cualquier otra institución funcione, se 
requiere que la lengua esté dividida en dos: por un lado, están los que meramente pueden comprender una orden, y por el otro encontramos a los que comprenden el problema que está detrás de la orden misma. El filósofo francés nos dice que el lenguaje presupone esta jerarquía de la siguiente manera:

En el uso ordinario, una expresión como “¿Usted me ha comprendido?" es una falsa interrogación donde el contenido afirmativo es el siguiente: "Usted no tienen nada que comprender", y de la misma manera y eventualmente: "Usted no está a la medida de comprender. Usted no tiene otra cosa que hacer sino obedecer”. Así, “¿Usted me ha comprendido?" es una expresión que nos dice precisamente que "comprender" quiere decir dos cosas diferentes, si no opuestas: comprender un problema y comprender una orden [traducción modificada] (Rancière 1995, 73).

El lenguaje, en consecuencia, presupone dos clases de seres hablantes y asimismo una relación armónica entre la palabra y la cosa o entre la palabra y su cuenta: una orden designa un objeto o una acción que se debe ejecutar. Ahora bien, detrás de la mera ejecución encontramos la comprensión del problema. El lenguaje otorga unos lugares específicos a unos cuerpos de acuerdo con un orden de la lengua. Teniendo en cuenta esto, la acción política desestabiliza dicho reparto de la palabra haciendo ver que, en dicha distinción en el orden del habla, se presupone una igualdad como punto de partida. Pero ¿cómo se pone de manifiesto que dicho reparto presupone una igualdad? ¿De qué modo se desestabiliza la frontera policial entre una lengua que comprende órdenes y otra lengua que comprende problemas?

Como ya lo hemos venido diciendo, es preciso que la acción política instituya un médium sensible en el que tendrían cabida unos trazos de sentido que desestabilizan las fronteras policiales de sentido que separan, por ejemplo, una lengua como posesión (hexis) y una lengua como comprensión (aisthesis). A juicio de Rancière, en esta institución política los que reciben las órdenes por parte de sus patrones responden de la siguiente manera:

Comprendemos que usted nos quiere enseñar que hay dos lenguas y que nosotros no podemos comprenderlo. Percibimos que usted hace 
eso para dividir (partager) el mundo entre aquellos que mandan y aquellos que obedecen. Al contrario, nosotros decimos que hay una sola lengua que nos es común y por tanto nosotros lo comprendemos así usted no quiera. En resumen, comprendemos que usted miente cuando niega que hay un lenguaje común [traducción modificada] (Rancière 1995, 75).

Este ejemplo, traído de los manifiestos obreros del siglo XIX, responde una y otra vez a los intentos de los patrones de negar que existe la posibilidad de discutir entre iguales en las fábricas, pues, en tal espacio, según los patrones mismos, no hay otra lógica que la de la administración y de la obediencia. Las palabras de los obreros tejen así un plano de inteligibilidad, en el que la palabra de aquellos que presuntamente comprenden meras órdenes manifiesta que la lengua es una $\mathrm{o}$, mejor aún, que la inteligencia es una; de ahí que no habría razón alguna para oponer una lengua de las órdenes y una lengua de las inteligencias. Este desplazamiento de sentido nos ofrece unos indicios esenciales de cómo la acción política instituye una escena en la que el sentido se divide ampliando y desestabilizando las fronteras policiales.

La acción política juega por tanto con apariencias, no para engañar u ocultar, sino para crear nuevos modos de experiencia común. Estos modos de experiencia común quedan inscritos en los relatos y en la sensibilidad que instituye la acción política, modificando así las coordenadas de interpretación de lo posible y de lo enunciable. Tenemos así que, a pesar de lo intermitentes y precarias que sean estas demostraciones, hay una especie de potencia poética que despliegan estas apuestas que cabe llamar "instituyentes". No porque instituyan un plano de sentido específico, sino porque figuran e ilustran trazos de sensibilidad disensuales que ponen una y otra vez en cuestión los criterios que definen nuestra experiencia común. Pero ¿por qué la institución de la acción política es siempre disensual? ¿Cómo comprender el sentido que instituye y produce dicha acción al no pretender instaurar un nuevo orden de significación necesario, universal y, por tanto, petrificado? La institución de la acción política siempre confronta un orden de sentido dado, pues crea trazos temporales de sentido que nos muestran que los 
criterios que organizan nuestra experiencia, de una forma universal y necesaria, pueden ser puestos en cuestión a través de escenas mostrativas que hacen nacer un mundo diferente dentro del mundo que habitamos. Este encuentro, como lo muestra George Didi-Huberman (2012) en su libro La supervivencia de las luciérnagas, es perfectamente equiparable a la tenue luz de las luciérnagas. Aparecen y desaparecen, son precarios pero ponen en discusión los criterios con los que tenemos una experiencia común. Desde esta perspectiva, las acciones emancipatorias no desaparecen definitivamente porque siempre nuestra sensibilidad y memoria estarán afectadas por el relato de aquellos que alguna vez, por diversas circunstancias, detuvieron la maquinaria de un mundo armónico, en el que las palabras tienen un correlato con ciertas prácticas y cosas. La acción política tiene, por ende, una efectividad, pues, produce un sentido disensual que confronta los criterios policiales con los que se trata lo común, tejiendo así una historia de pequeñas escenas que afectan aquello que es enunciable e incluso posible.

Teniendo en cuenta lo anterior, la acción política no se opone a la institución, pues, en sentido estricto, la primera desestabiliza las fronteras de sentido que separan una acción pura y una institución jurídica. Como se pudo ver en este apartado, la acción hace confluir expresiones y prácticas heterogéneas en un mismo escenario. Dicha institución es móvil y disensual, pues pone a jugar nuestras facultades de la imaginación y el entendimiento del mismo modo como Kant (2012) lo puso de manifiesto con los juicios del gusto. No obstante, ¿a qué tipo de institución nos arroja esta comprensión? ¿De qué modo el recuerdo o los logros de las acciones anteriores posibilitan el porvenir de acciones futuras? En lo que resta de este artículo, nos encargaremos de mostrar cómo la acción, además de instituir un conjunto de modos de sensibilidad, se sirve de recuerdos y de instituciones para poner en marcha ciertas apuestas emancipatorias.

\section{La institución y la acción}

La acción no instituye su médium sensible ex nihilo, porque se sirve de palabras previamente existentes, pero combinadas y ensambladas de una forma polémica. Por eso, como lo precisábamos unas líneas más 
arriba, la acción supone el encuentro de elementos heterogéneos, dividiendo así el sentido de una palabra o de una práctica. El derecho deja de remitir a una ciudadanía existente, para ser el derecho de aquellos que reclaman una ciudadanía, o los asuntos, que no son en sentido estricto políticos, dejan de estar confinados a las relaciones privadas para volverse del interés común, tales como las relaciones laborales y la voz que adquieren las integrantes de los movimientos de mujeres. Tenemos así que la acción cuenta con elementos que la hacen posible, si bien, en estricto sentido, tales elementos no son políticos. El lenguaje común o el derecho mismo no tienen que ver con la política; sin embargo, al ponerse de manifiesto una comprensión polémica de la lengua o del derecho, se abre un espacio político en el que la acción altera el mundo que habitamos. Pero ¿qué es lo que promueve que hagamos un uso polémico del derecho o de la lengua? ¿De qué modo algo que no es estrictamente polémico puede llegar a serlo y a la vez lo que permitiría la acción misma?

Como lo precisábamos al inicio, Butler (2012) nos dice que la acción política tiene un soporte, aun cuando pretende reclamar dichos soportes. Los sistemas de seguridad social o el acceso a unas condiciones de vida dignas son, en muchos casos, aquello que hace posible la acción $y$, al mismo tiempo, el contenido de sus reclamos o razones de lucha, lo cual nos arroja al siguiente dilema que ya anotábamos:

No podemos actuar sin apoyos, y sin embargo tenemos que luchar por los apoyos que nos permiten actuar [...] Los soportes materiales de la acción no son sólo parte de la acción, sino también aquello en torno a lo que se está luchando, especialmente en aquellos casos en que la lucha política se da por alimento, empleo, movilidad y el acceso a instituciones (Butler, 2012, 12).

Este dilema no es fácil de resolver o al menos de abordar, pues Butler nos está diciendo que la institución de la acción política tiene una suerte de condiciones de posibilidad al mismo tiempo que la garantía de tales condiciones son el objetivo de la acción misma. Este dilema plantea al menos dos problemas. El primero de ellos tiene que ver en cómo la acción 
se sirve de palabras, recuerdos y apuestas previamente existentes, para poner en entredicho los criterios de inclusión y exclusión en una comunidad específica. En segundo lugar, el dilema nos arroja a la necesidad de pensar en una institución que, si bien no sea equivalente a la acción, pueda preservar su carácter insurreccional, como una suerte de medio en el que se desenvuelve la acción, claro está, siempre excediéndolo.

Teniendo en cuenta el primer problema, el caso del sufragio universal resulta significativo. Desde cierta perspectiva predominante, dicho derecho nos remite a la oposición entre democracia formal y democracia real, pues la primera es equivalente a una suerte de gobierno oligárquico que no logra realizar plenamente los derechos políticos de una comunidad; de ahí que una verdadera política, o una verdadera participación por parte del pueblo, sea la democracia directa o real, es decir, una democracia que no esté mediada por el Estado, ya que la verdadera política estaría contenida en la emancipación humana y no en la emancipación político-jurídica (Marx, 2012). Ahora bien, diremos, en cambio, que el sufragio universal no es una institución del gobierno de unos pocos ni tampoco la manifestación de un poder que aliena el poder popular, porque

el sufragio universal es una forma mixta nacida de la oligarquía, desviada del combate democrático y perpetuamente reconquistada por esa oligarquía que propone sus candidatos y a veces sus decisiones a la elección del cuerpo electoral, sin poder excluir jamás el riesgo de que el cuerpo electoral se comporte como una población de sorteo (Rancière 2007, 79-80).

Tenemos así que el derecho político del sufragio universal no es estrictamente un mecanismo de participación popular ni tampoco una institución que niega el poder democrático del pueblo, porque, en muchos casos, los derechos consignados en las instituciones estatales son las condiciones de posibilidad para abrir las esferas de la participación política a otros actores que carecen de títulos de gobierno. El sufragio universal es, en consecuencia, un medio y a la vez un fin de lucha, pues, con el voto se espera que se rompa con un mecanismo 
oligárquico que se ha consolidado a través del sufragio mismo, lo cual nos obliga, por tanto, a decir que la acción política necesita una suerte de espacio de aparición, pero este espacio es construido por la acción, al mismo tiempo que se sirve de derechos, sentidos y recuerdos ya instituidos. Teniendo en cuenta esto, resulta comprensible cómo, a juicio de Rancière (2007), los derecho de ciudadanía no son meras formalidades que se oponen a la realidad ni tampoco los derechos de quienes tienen derechos, ${ }^{3}$ sino más bien son inscripciones de anteriores acciones políticas, que, pese a su carácter aparentemente desigualitario, pueden permitir crear un escenario de mostración, en el que los derechos mismos son condiciones de posibilidad para que una acción política tenga lugar (Rancière 2004, 7).

Los movimientos sociales son la expresión contemporánea de estas apuestas de lucha que se sirven de derechos consignados en ordenamientos constitucionales cuando se demanda, por ejemplo, que la soberanía no es del capital ni de los inversores, sino de los pueblos; o que los mecanismos de legislación y de participación electoral deben estar subordinados a las dinámicas político-organizativas de los movimientos de base. Este fue el caso del movimiento político y popular llamado "Los inconformes" en el Departamento de Nariño en Colombia en la década de los ochentas. Como lo reseña la investigadora del Cinep Martha García, "Los inconformes" nacieron de la confluencia de sesenta organizaciones populares de diversa procedencia en enero de 1983. Una de las decisiones de este movimiento consistió en servirse del sufragio universal para lograr unos puestos estratégicos de representación polí-

3 Hannah Arendt (2006) en Los orígenes del totalitarismo, en especial en el apartado titulado "La decadencia del Estado nación y el final de los derecho humanos", nos dice que aquello significativo que nos deja como legado la experiencia totalitaria consiste en la posibilidad de que a los seres humanos se les nieguen sus derechos fundamentales al negarle su derecho a tener derechos. La fórmula es simple como crucial: la ciudadanía, antes que nada, se vuelve el elemento esencial para que un ser humano sea concebido como garante de derechos. De modo que a aquellos que no tienen un reconocimiento de ciudadanía se les despoje de un derecho primordial: del derecho a tener derechos. Teniendo en cuenta eso, la pertenencia jurídica a una comunidad específica definiría a los ciudadanos como aquellos que tienen el derecho a tener derechos y a las masas que se quedaron sin sus derechos de ciudadanía como aquellos que no tienen el derecho a tener derechos. 
tica al mismo tiempo que presionaban al gobierno central a través de paros cívicos. El resultado fue tan evidente que "Los inconformes" obtuvieron ocho alcaldías en 1988 logrando así establecer canales de negociación con el gobierno central, capacidad que no tenían los partidos tradicionales en Nariño (García, 2009). El sufragio universal fue el apoyo de este movimiento en al medida en que su accionar subordinó la agenda electoral a la movilización popular y a lo que ellos mismos denominaban "trabajo de base". El derecho, desde esta perspectiva, el derecho hace posible a la acción aún cuando la acción misma exceda la función jurídica del "derecho al voto". Tenemos así, que acción e institución se presuponen mutuamente en el instante en el que un derecho determinado se vuelve entonces un medio y a la vez un fin de la lucha de acciones emancipatorias. Es un medio porque sin este soporte no sería posible llevar a cabo una apuesta transformadora, y es un fin porque se pretende transformar los mecanismo jurídico-políticos en espacios emancipatorios. Ahora bien, como ya lo precisábamos antes, surge un segundo problema que podemos formular de la siguiente manera: si bien existe una presuposición mutua entre institución y acción en el momento de la manifestación política ¿cómo concebir una institución que preserve el carácter insurreccional de la acción? ¿De qué manera pensar una relación entre acción e institución que no parta del supuesto de oponerlas radicalmente?

Este es el problema que aborda Tassin (2012) en Le maléfice de la vie à plusieurs. Teniendo en cuenta la aproximación de Arendt (2013), Abensour (1998) y Merleau-Ponty (1968), Tassin intenta introducirnos en una comprensión de la institución que parta de una suerte de revolución permanente, en la que se interiorice "la contestación que preserva la dimensión creativa de la insurrección, su dinámica histórica” (171). Con esto, podemos decir que la mutua presuposición entre acción política e institución nos arroja a la necesidad de concebir un espacio que se preste para una posibilidad de insurrección permanente. Ahora bien, la comprensión que pretende desplegar el filósofo francés busca mostrar que, si bien la acción política jamás se podrá instaurar como una suerte de régimen jurídico-político, puede haber la posibilidad de concebir una institución que preserve la posibilidad contestataria de la acción — sin 
tener, claro está, que negarla con miras a establecer un orden nuevo-. Para llevar a cabo este objetivo, tendremos que poner juntas, juicio de Tassin, dos ideas que son antagónicas:

La idea, por una parte, de que los conflictos son perennes, reconducidos e insolubles, es decir, la idea de que bajo la revolución yace siempre otra revolución y que esa división estructural de la sociedad es el medio de la vida; por otra, la idea de que los combates de los hombres se libran por su libertad o por sus intereses no son jamás inútiles o desesperados aun cuando de estos no salga una solución, puesto que algo de nuevo llega y hace historia gracias a ellos (176).

Desde esa perspectiva, tenemos que, si juntamos estas dos ideas, es decir, la idea de que el conflicto no se puede terminar y la idea de que las acciones tienen cierta efectividad, podemos ir ensamblado una idea de una institución que, más allá de ser sinónimo de estructuras jurídico-políticas fijas, es, a la vez, acto y proceso, de modo que la institución se convierte en aquello que hace posible la acción y, asimismo, una suerte de organización de lo común que prolonga la posibilidad de que la acción insurgente pueda manifestarse. Si antes habíamos dicho que la acción hace uso de instituciones previamente existentes para figurar el mundo de otra manera, en este caso la institución nos invita a comprender la configuración de un cuerpo político que deja abierto el sentido y las fronteras que delimitan posibilidad e imposibilidad abiertas. Pero ¿qué significa un cuerpo político o una institución que deje abierto el sentido a otros modos de ensamblaje de lo real? ¿Cómo esbozar una comprensión de la institución que parta del supuesto de una conflictividad en la vida en común y asimismo tenga en cuenta que todo acto tiene una efectividad en los modos en los que interpretamos el mundo común?

Para este esquema, según el cual la institución preserva el carácter contestatario de la acción, el sujeto no se entiende "como un actor soberano de sus propios actos, sino desde las modalidades de su actuar, de su hacer que se encuentran en los ojos de otros y no simplemente en sus propios ojos" (Tassin 2012, 180). La institución es, por ende, una suerte de medio en el que se teje una vida en común en la medida en que la 
mirada de los otros o la proximidad a una alteridad excede la identidad individual de un sujeto soberano que se subordina a los mandatos de una ley. Tenemos así que el problema de la relación entre acción e institución se plantea no tanto respecto de cómo la institución traiciona la acción con el afán de garantizar una estabilidad política, sino más bien cómo "la institución puede preservar, en el tiempo, las posibilidades que encierra la democracia y su dimensión insurgente" (Tassin 2012, 184).

Siguiendo este punto de vista, una institución política no es un entramado jurídico que asegura el imperio de la ley y de la constitución sobre las acciones de la denominada sociedad civil, ${ }^{4}$ sino más bien es un entramado normativo que potencia y preserva la contestación de la acción política, es decir, es un marco que promueve una politización de la vida sin asegurarla, pues, como ya lo hemos venido sosteniendo, la acción se caracteriza por exceder aquello que está instituido. La institución, que es producto de la acción y al mismo tiempo aquello de que se sirve la acción para excederla, nos invita a concebir la institución política como un conjunto de normas que permiten hacer inteligibles diversos modos de comprender el sentido. Con esto, una norma política es aquella que nos dice que "la soberanía reside exclusivamente en el pueblo", al mismo tiempo que nos invita a reinterpretar qué quiere decir la soberanía popular de modo polémico, incluso más allá, por ejemplo, de la representación política. Una norma política preserva el carácter insurgente de la acción en cuanto dicha norma es deudora de la acción misma. Alguna vez una acción política inscribió la igualdad de los ciudadanos en las normas de las instituciones, así como en algún momento el pueblo entró en escena para reclamar su lugar en la decisión sobre los asuntos comunes. Una institución política o un cuerpo político que preserve la acción es aquel que se concibe a sí mismo como un efecto histórico de un conjunto de transformaciones y de apuestas

4 Desde la perspectiva de Jürgen Habermas (2007), las tramas organizativas que se tejen alrededor de la exigencia de una participación política es denominada la sociedad civil. Esta sociedad se caracteriza por asumir una preponderancia de la ley en los procedimientos de deliberación pública para que sus demandas sean vinculantes para todos los miembros de una comunidad política. De ahí podemos decir que la justicia y la efectividad de las apuestas democráticas solo son justificables en el plano de una subordinación de la acción a la ley. 
emancipatorias, de ahí que asuma que la acción siempre excederá el sentido consignado en sus normas. La institución es, en consecuencia, una suerte de plano de inteligibilidad, que traza ciertas modalidades de interpretar lo real movido en la contingencia que instituye la acción; pero, al mismo tiempo, la hace posible, pues sin institución o sin sentido instituido no sería posible actuar políticamente.

Si queremos encontrar un ejemplo de esta aproximación a la institución como medio en el que se desenvuelve la acción - siempre excediendo toda norma-, resulta preciso traer la deleuziana noción de 'plano de inmanencia. En ¿Qué es la filosofía?, Deleuze y Guattari (2005) nos muestran que los conceptos son una serie de inscripciones y acontecimientos que trazan unas líneas concretas de inteligibilidad en el caos. Los conceptos instituyen sentido $\mathrm{y}$, asimismo, unas coordenadas de interpretación de lo real que conserva, en gran medida, la contingencia misma de la cual se nutre. Ahora bien, Deleuze y Guattari nos dicen que, si bien los conceptos son acontecimientos, el plano es "el horizonte de esos acontecimientos conceptuales: no el horizonte relativo que funciona como un límite, que cambia con un observador y que engloba estados de cosas observables, sino el horizonte absoluto, independiente de cualquier observador" $(2005,40)$. El plano de inmanencia es, entonces, un horizonte que hace posible que tengamos experiencia de mundo, por eso, todo intento por interpretar la realidad está atravesado por ese horizonte abierto que hace circular el sentido a velocidades infinititas, es decir, de una forma contingente. Como resulta evidente, el plano de inmanencia es un marco de posibilidades en el que se tejen y se ensamblan prácticas, sentidos, significados y modos de figuración en el que intervienen los conceptos. De ahí cobran significado las siguientes palabras:

[...] evidentemente el plano no consiste en un programa, un propósito, un objetivo o un medio; se trata de un plano de inmanencia que constituye el suelo absoluto de la filosofía, su Tierra o su desterritorialización, su fundación, sobre los que crea los conceptos (45).

El plano de inmanencia brinda, entonces, una consistencia sin perder lo infinito, es decir, sin perder la infinitud de posibilidades de 
enunciación y de ensamblaje de lo real. Por eso, podemos decir que la institución o el cuerpo político, que asegura las condiciones de posibilidad para que la acción política tenga lugar, exhibe una función equiparable a la del plano de inmanencia deleuziano, porque, más allá de ser un mundo de sentido petrificado, es un conjunto de formas y de posibilidades que preserva el carácter contingente del sentido mismo. La acción política, lejos de interrumpir y oponerse a un sentido instituido, necesita cierto entramado de significados para movilizar un conjunto de palabras y prácticas que reconfiguran los presupuestos con los que está tejida nuestra experiencia común. La acción, además de ser instituyente, necesita un medio instituido que preserva la posibilidad de exceder el medio mismo. La institución, desde esta perspectiva, es un presente vivo o una duración creadora, ${ }^{5}$ que nos muestra que toda acción no se agota en su mera manifestación, ni tampoco nos muestra cómo el cuerpo político instituido es una estructura petrificada que fija un régimen de estabilidades, sino en la inmanencia de un conjunto de instituciones y de sentidos instituidos que circulan contingentemente en nuestra experiencia común. La acción, entonces, tiene cierta efectividad, pues, además de figurar nuevos ensamblajes de lo real -en el momento de hacer encontrar procesos heterogéneos - instituye sentidos que harán posible el porvenir de la acción política.

\section{A modo de conclusión}

Hemos dicho que desde ciertos enfoques predominantes de concebir la acción política existe una oposición hasta cierto punto dicotómica entre acción e institución. Para criticar esta idea nos hemos servido de algunas apuestas filosófico-políticas que intentan desplegar una comprensión no dicotómica entre las manifestaciones emancipatorias y sus inscripciones institucionales. Como quedó expuesto en la

5 Tassin $(2012,178)$ nos muestra que esta duración creadora o este presente vivo parte del supuesto de una comprensión del tiempo específica. No se trata acá de oponer el tiempo del surgimiento de la acción al tiempo de las estabilidades, sino más bien de mostrar cómo la acción pervive en un entramado creador que asegura el carácter insurreccional de la acción sin fijarla en un esquema normativo. 
primera parte de este artículo, la acción política no es la mera interrupción de unas instituciones petrificadas que buscan ordenar el mundo a través de la violencia, sino más bien es un proceso en el que se instituyen nuevas coordenadas de sentido que permiten interpretar y tener experiencia de la realidad. Esta institución de nuevos sentidos juega con palabras y prácticas existentes previamente, pero combinadas de una forma inédita y, por tanto, polémica. Expresiones como el derecho de los oprimidos o la moral del militante son combinaciones de palabras y prácticas que instituyen un plano de inteligibilidad polémico, en el que se reensamblan las condiciones de posibilidad con las que tenemos experiencia de mundo. Ahora bien, este sentido instituyente de la acción se complementa con su carácter instituido, pues, como pudimos dar cuenta, la acción política necesita un medio para actuar. Este medio es una suerte de trama institucional que abre la posibilidad de contestación por parte de la acción, aunque la acción misma siempre exceda aquello que pretende garantizarla. De ahí cobra significado la perspectiva de Butler (2012), según la cual la acción se apoya en aquello que ella misma reclama. Por último, resulta preciso decir que, para comprender una relación no dicotómica entre acción e institución, pretendimos esbozar una suerte de comprensión de la institución como acto y proceso, en la que se pone en marcha una duración creadora en la que el sentido queda expuesto a una multiplicidad de ensamblajes. Las instituciones - a pesar de no ser en estricto sentido políticas- establecen un cuerpo político que brinda el medio y las condiciones de posibilidad para que la acción tenga lugar. La acción política no es mera resistencia ni mucho menos un conjunto de demandas que requieren cierta institucionalización, sino más bien es un proceso que afecta el modo en el que interpretamos la realidad produciendo polémicamente sentidos que irrumpen en la usual reproducción de un mundo dividido entre quienes concentran la decisión sobre los asuntos comunes y aquellos despojados de su potencia de actuar. 


\section{Referencias bibliográficas}

Abensour, M. 1998. La democracia contra el Estado. Buenos Aires: Colihue.

Agamben, Giorgio. 2006. Homo sacer. Madrid: Pre-Textos.

Arendt, Hannah. 2007. Los orígenes del totalitarismo. Madrid: Alianza.

Arendt, Hannah. 2013. Sobre la revolución. Madrid: Alianza.

Aristóteles. 2003. Política. Madrid: Alianza.

Benjamin, Walter. 2009a. "Para una crítica de la violencia”. En Estética y política. Buenos Aires: La Cuarenta.

Benjamin, Walter. 2009b. "Sobre el concepto de historia”. En Estética y política. Buenos Aires: La Cuarenta.

Butler, Judith. 2012. “Cuerpos en alianza y la política de la calle”. Revista Transversales 26.

Deleuze, Gilles y Felix Guattari. 2005. ¿Qué es la filosofía? Barcelona: Anagrama.

Didi-Huberman, Georges. 2012. Supervivencia de las luciérnagas. Madrid: Abada.

Esposito, R. Bíos: biopolítica y filosofía. Buenos Aires: Amorrortu.

García, Martha. 2009. "El movimiento cívico por Nariño”. En Una historia inconclusa: izquierdas politicas y sociales en Colombia, ed. Mauricio Archila et al. Bogotá: Cinep.

Habermas, Jürgen. 2005. Facticidad y validez. Madrid: Trotta.

Kant, E. 2012. Crítica del discernimiento. Madrid: alianza.

Marchart, Oliver y Marta Delfina Álvarez. 2009. El pensamiento político posfundacional: la diferencia política en Nancy, Lefort, Badiou y Laclau. México: Fondo de Cultura Económica.

Marx, K. 2012. Sobre la cuestión judía. Buenos Aires: Prometeo.

Merleau-Ponty, M. 1968. Résumés de cours. París: Gallimard.

Nancy, J. 1996. La comunidad desobrada. Buenos Aires: Arena Libros.

Rancière, Jacques. 1995. La mésentente. París: Galileé.

Rancière, Jacques. 2004. "Who is the subject of the Rights of Man". En 
The south Atlantic Quarterly. Carolina del Norte: Duke University Press.

Rancière, Jacques. 2007. El odio a la democracia. Buenos Aires: Amorrortu.

Rancière, Jacques. 2010. El desacuerdo. Buenos Aires: Nueva Visión.

Rancière, Jacques. 2011. El malestar en la estética. Buenos Aires: Capital Intelectual.

Rancière, Jacques. 2012. Le methode de l'egalité. París: Bayard.

Schmitt, Carl. 2008. “Teología política I”. En Carl Schmitt: teólogo de la política. México: Fondo de Cultura Económica.

Tassin, Étienne. 2012. Le maléfice de la vie à plusieurs: la politique est-elle vouée à l'échec? París: Bayard. 